\title{
Polipose nasossinusal: doença inflamatória crônica evolutiva?
}

\author{
Bruno Beltrão de Souza ${ }^{1}$, Marcelo Fenile Serra ${ }^{1}$, \\ João Vicente Dorgam ${ }^{1}$, Sabrina Maria de Castro \\ Sarreta ${ }^{1}$, Valder Rodrigues de Melo², \\ Wilma T. Anselmo-Lima
}

\section{Nasal polyposys: a chronic inflammatory progressive disease?}

Palavras-chave: polipose, doença inflamatória crônica, alterações ultraestruturais.

Key words: polyposis, chronic inflammatory disease, ultrastructural alterations.

\section{Resumo / Summary}

ntrodução: A polipose nasossinusal é uma doença degenerativa da mucosa onde há formação de múltiplas estruturas polipóides nas cavidades nasais e seios paranasais e cujos mecanismos fisiopatológicos ainda não são bem compreendidos. Forma de estudo: Clínico prospectivo. Objetivo e Material e Método: Objetivando colaborar na compreensão dos fatores envolvidos na patogênese dos pólipos nasais, decidimos estudar a histologia e a ultraestrutura dos pólipos em dezessete pacientes portadores de polipose. Os pacientes foram divididos em 2 grupos: alérgicos ( 5 pacientes) e não alérgicos (12 pacientes). Resultados: Mucosa respiratória normal cobrindo a superfície do epitélio foi encontrada em oito casos; metaplasia escamosa em quatro casos; diferentes tipos epiteliais em três casos; epitélio respiratório atípico em um caso e ausência de mucosa em um caso. Foram observados quatorze casos de pólipo tipo fibro-inflamatório, um caso de hiperplasia de glândulas seromucinosas e dois casos de pólipos fibróticos. Conclusões: Os pacientes apresentaram índices de testes cutâneos positivos iguais ou maiores que a população geral, entretanto, não houve diferenças histológicas ou ultraestruturais entre os pólipos de pacientes alérgicos e dos não alérgicos, sugerindo ser a alergia um fator contribuinte mas não causal na fisiopatologia da polipose nasossinusal. ntroduction: Nasosinusal polyposis is a degenerative disease of the mucosa with the formation of multiple polypoid structures in the nasal cavities and facial sinuses whose physiopathological mechanisms are not well understood. Study design: Clinical prospective. Aim and Material and Method: In order to contribute to the understanding of the factors involved in the pathogenesis of nasal polyps we decided to study the histology and ultrastructure of the polyps in 17 patients with polyposis. The patients were divided into two groups: allergic (5 patients) and non-allergic (12 patients). Results: A normal respiratory mucosa covering the surface of the epithelium was detected in eight cases, squamous metaplasia in four, different epithelial types in three, atypical respiratory epithelium in one, and absence of mucosa in one. We observed 14 cases of polyps of the fibro-inflammatory type, one case of seromucinous gland hyperplasia, and two cases of fibrotic polyps. Conclusions: The patients presented rates of positive skin test equal to or higher than those of the general population. However, there were no histological or ultrastructural differences betw een the polyps of allergic and non-allergic patients, suggesting that allergy is a contributing but not a causal factor in the physiopathology of nasosinusal polyposis.

${ }^{1}$ Pós-Graduandos, Nível Mestrado, do Departamento de O torrinolaringologia da FMRP-USP

2 Professor Doutor do Departamento de Cirurgia e Anatomia da FMRP-USP.

3 Professora Associada do Departamento de Otorrinolaringologia da FMRP-USP.

Endereço para Correspondência: Profa. Dra. Wilma T. Anselmo-Lima - Departamento de O ftalmologia e O torrinolaringologia e

Cirurgia de Cabeça e Pescoço do HCFMRP-USP - Av. Bandeirantes, 3900 Ribeirão Preto SP 14049-900

Tel (0xx16) 602-2862 - Fax (0xx16) 602-2860.

Apresentado no II Congresso Triológico de Otorrinolaringologia da SBORL, Goiânia, 2001.

Artigo recebido em 10 de março de 2003. Artigo aceito em 13 de maio de 2003. 


\section{INTRODUÇÃO}

A Polipose Nasossinusal (PN) é uma doença inflamatória crônica da mucosa respiratória nasal e dos seios paranasais que se manifesta clinicamente pelo aparecimento de formações polipóides, geralmente bilaterais e que levam à obstrução nasal, rinorréia, hiposmia ou anosmia e rinossinusites de repetição. Para Caplin et al. 1971'1 acomete 0,5 a $4 \%$ da população e sua patogenia, correlação com alergia e tratamento eletivo são alvo de controvérsia.

A presença de um processo inflamatório crônico na submucosa parece ser um elemento comum a todos os casos de PN, o que pode ser evidenciado em diversos trabalhos na literatura. Segundo Norlander et al. ${ }^{2}, 1999$, há um considerável incremento de mediadores inflamatórios na submucosa do pólipo e mucosa adjacente. Os efeitos combinados de citocinas e fatores de crescimento produzidos por linfócitos T, fibroblastos, células epiteliais e células circulantes, principalmente eosinófilos, podem ser responsáveis pelas diversas fases do processo de formação do pólipo.

Ainda há muito que se entender na patogenia da PN. A inflamação crônica é um dos principais fatores implicados, entretanto, nem todas as doenças inflamatórias crônicas da mucosa cursam com PN, como é o caso das rinossinusites crônicas. Da mesma forma, a diminuição do fluxo aéreo por bloqueio anatômico com conseqüente redução da concentração de $\mathrm{O}$, tissular ocorre na maioria dos casos, mas também não é um fator estritamente necessário na patogenia.

Atualmente há uma tendência na literatura em considerar a PN como uma doença inflamatória de causa multifatorial ${ }^{3}$. Fatores locais como infecção bacteriana ou alterações estruturais como desvios de septo e variações anatômicas do meato médio resultam em uma resposta inflamatória local, que é responsável pelo aparecimento de ulcerações mucosas com conseqüente prolapso da submucosa, desencadeando reepitelização e proliferação glandular. Fibroblastos e células epiteliais atuam produzindo citocinas, fatores quimiotáticos e outros mediadores que perpetuarão o processo inflamatório. Em decorrência destes eventos, a absorção de íons no estroma fica alterada, como demonstram trabalhos deste mesmo autor, levando a maior edema e crescimento do pólipo. Predisposição genética também pode estar implicada nesta patogenia.

0 presente estudo visa estudar morfologicamente, através de microscopia óptica e eletrônica, as alterações estruturais na PN, enfocando principalmente 0 infiltrado inflamatório e o possível papel da alergia nesta fisiopatologia.

\section{MATERIAL E MÉTODO}

Foram estudados dezessete pacientes portado res de polipose nasossinusal do Ambulatório de Rinossinusologia. A idade dos pacientes variou de 9 a 77 anos, com média de
42,6 anos, sendo 9 do sexo masculino e 8 do sexo feminino.

Critérios de inclusão: Foram incluídos no estudo pacientes portadores de polipose nasossinusal bilateral que não apresentaram resposta terapêutica após 6 meses de tratamento clínico convencional a base de corticosteróides tópicos e sistêmicos e antibioticoterapia de amplo espectro, tendo sido submetidos então a tratamento cirúrgico. Os espécimens foram obtidos pela técnica cirúrgica endoscópica. Critérios de exclusão: foram excluídos os portadores de doenças associadas, especialmente fibrose cística, discinesia ciliar e das Síndromes de Y oung e de Churg-Strauss.

0 estudo foi aprovado pelo Comitê de Ética em Pesquisa do HC-FMRP-USP de acordo com o processo no 1930/97.

Os pacientes foram divididos em 2 grupos:

- Grupo alérgico (5 pacientes)

Q uadro clínico compatível com rinite alérgica (obstrução nasal, espirros, rinorréia e prurido); teste cutâneo de hipersensibilidade positivo.

- Grupo sem alergia (12 pacientes)

Ausência de sinto mas de rinite alérgica; teste cutâneo de hipersensibilidade negativo.

\section{Preparo do Material para Exame Histológico e Ultraestrutural}

\section{Microscopia Óptica (MO)}

Os pólipos foram classificados histologicamente em quatro tipos: eosinofílico; fibro-inflamatório; pólipo com hiperplastia de glândulas seromucinosas e pólipo com estroma atípico. A coleta dos pólipos foi efetuada durante o ato cirúrgico, fixando-os em formol para posterior coloração com hematoxilina e eosina.

\section{Microscopia Eletrônica de Transmissão (MET)}

Coletados fragmentos de pólipos de mais ou menos $0.3 \mathrm{~mm}$ de diâmetro cada, lavados em solução salina (S.F. $0,9 \%)$, passando a fixação com glutaraldeído (3\%) por 2 horas a $4^{\circ} \mathrm{C}$. Após a fixação, os fragmentos foram lavados em tampão fosfato (0.1M). A seguir foram pós-fixados em tetróxido de ósmio a $1 \%$ por 2 horas a $4^{\circ} \mathrm{C}$, lavados 3 vezes em tampão fosfato (0.1M) sendo então desidratados em uma série crescente de acetona: 30, 50, 70, 90, 95 e 100\%. Em seguida foi incluído em resina araldite por 72 horas a $60^{\circ} \mathrm{C}$ e levado para realização de cortes semi-finos e ultra-finos obtidos com navalha de vidro e diamante (respectivamente). Os semi-finos $(0.5 \mu)$ foram corados com azul de toluidina e fotografados em microscópio Zeiss. Os cortes ultrafinos (600 A) foram colhido em grades de cobre (200 mesh); contrastados em acetato de uranila (4\%); lavados 4 vezes em água e em citrato de chumbo (0,3\%) por 15 minutos; lavados 4 vezes em água MilliQ. Esses cortes foram 
observados em microscópio eletrônico de transmissão Philips 208 operando em $80 \mathrm{kv}$. Os espécimes foram processados, observados e eletronmicrografados no Laboratório de Microscopia Eletrônica do Departamento de Morfologia da Faculdade de Medicina de Ribeirão Preto-USP.

\section{RESULTADOS}

\section{Caracterização dos Grupos de Pacientes}

$\mathrm{Na}$ tentativa de se caracterizar 2 grupos de pacientes alérgicos e não alérgicos, decidimos avaliar os mesmos com história clínica, teste cutâneo e dosagem de IgE total. Cinco pacientes foram selecionados para compor 0 grupo 1 \# pacientes alérgicos. Eles apresentavam história de alergia e teste cutâneo positivo. Em outros pacientes, apesar de alguns apresentarem história de alergia e dosagem de IgE total acima do normal, o teste cutâneo foi negativo, sendo então considerados como não alérgicos (Tabelas 1 e 2).

\section{Estudo Histológico e Ultraestrutural}

Os pacientes tiveram várias amostras dos pólipos exaustivamente estudadas à microscopia óptica e eletrônica de transmissão para caracterizar o tipo de epitélio da mucosa. Nos pacientes do Grupo 1, epitélio respiratório normal foi encontrado em dois casos, epitélio respiratório atípico em um caso, metaplásico em um caso e um caso com ausência de mucosa (Tabela 3).

Nos pacientes do Grupo 2, epitélio respiratório normal foi encontrado em seis casos, diferentes tipos epiteliais em três casos e metaplásico nos últimos três casos (Tabela 4).

A submucosa dos pacientes de ambos os grupos foi estudada de acordo com a classificação proposta por Davidsson et al. em $1993^{4}$.

Nos pacientes do grupo 1 (alérgicos) encontramos três casos de pólipos fibro-inflamatórios e dois casos do tipo fibrótico não encontrado na classificação de Davidsson et al. (Tabela 5).

Nos pacientes do Grupo 2 (não alérgicos) encontramos um caso de hiperplasia de glândulas seromucinosas; os outros onze eram fibro-inflamatórios. Nenhum caso de pólipo eosinofílico ou atipia de estroma foi identificado (Tabela 6).

Tabela 1. Grupo 1: pacientes considerados alérgicos

\begin{tabular}{cccccc}
\hline Caso & Sexo & Idade & $\begin{array}{c}\text { História } \\
\text { de Alergia }\end{array}$ & $\begin{array}{c}\text { Teste } \\
\text { Cutâneo }\end{array}$ & $\begin{array}{c}\text { Níveis de } \\
\text { IgE Total }\end{array}$ \\
\hline 1 & $M$ & 58 & + & + & 334 \\
2 & $\mathrm{~F}$ & 33 & + & + & 141 \\
3 & $M$ & 52 & + & + & 299 \\
4 & $M$ & 11 & + & + & 1904 \\
5 & $\mathrm{~F}$ & 36 & + & + & 63 \\
\hline
\end{tabular}

Tabela 2. Grupo 2: pacientes considerados não alérgicos

\begin{tabular}{cccccc}
\hline Caso & Sexo & Idade & $\begin{array}{c}\text { História } \\
\text { de Alergia }\end{array}$ & $\begin{array}{c}\text { Teste } \\
\text { Cutâneo }\end{array}$ & $\begin{array}{c}\text { Níveis de } \\
\text { IgE Total }\end{array}$ \\
\hline 1 & $F$ & 78 & - & - & 1363 \\
2 & $F$ & 17 & - & - & 3515 \\
3 & $F$ & 29 & - & - & 72 \\
4 & $F$ & 36 & - & - & 134 \\
5 & $F$ & 30 & - & - & 140 \\
6 & $M$ & 27 & - & - & 18 \\
7 & $F$ & 59 & - & - & 189 \\
8 & $F$ & 47 & + & - & 77 \\
9 & $M$ & 59 & + & - & 27 \\
10 & $M$ & 36 & + & - & 273 \\
11 & $M$ & 43 & + & - & 120 \\
12 & $M$ & 73 & + & - & 2273 \\
\hline
\end{tabular}

Tabela 3. Tipos de epitélios encontrados nos pacientes do Grupo 1

\begin{tabular}{lc}
\hline \multicolumn{1}{c}{ Tipos de Epitélios } & Número de Casos \\
\hline Epitélio respiratório normal & 2 \\
Epitélio respiratório atípico & 1 \\
Epitélio metaplásico & 1 \\
Ausência de mucosa & 1 \\
\hline
\end{tabular}

Tabela 4. Tipos de epitélios encontrados nos pacientes do Grupo 2

\begin{tabular}{lc}
\hline \multicolumn{1}{c}{ Tipos de Epitélios } & Número de Casos \\
\hline Epitélio respiratório normal & 6 \\
Diferentes tipos epiteliais & 3 \\
Epitélio metaplásico & 3 \\
\hline
\end{tabular}

Tabela 5. Tipos de pólipos encontrados nos pacientes do Grupo 1

\begin{tabular}{lc}
\hline \multicolumn{1}{c}{ Tipos de Pólipos } & Número de Casos \\
\hline Fibro-inflamatório & 3 \\
Fibrótico & 2 \\
\hline
\end{tabular}

Tabela 6. Tipos de pólipos encontrados nos pacientes do Grupo 2

\begin{tabular}{lc}
\hline \multicolumn{1}{c}{ Tipos de Pólipos } & Número de Casos \\
\hline Fibro-inflamatório & 11 \\
Hiperplasia de glândulas & 1 \\
seromucinosas & \\
\hline
\end{tabular}


Dessa forma, mucosa respiratória normal cobrindo a superfície do pólipo foi encontrada em oito casos: ou seja, epitélio pseudoestratificado ciliado com células caliciformes e cílios cuja morfologia estava normal (Figura 1). 0 aumento descrito nas fotos corresponde ao aumento original.

Epitélio respiratório atípico foi visto em um caso: diminuição importante no número de células ciliadas e no número de cílios (Figura 2). Epitélio metaplásico, com células escamosas planas e ausência total de cílios foi evidenciado em quatro casos (Figura 3). Em três casos foram observadas áreas de metaplasia escamosa e áreas de epitélio atípico: mucosa com diminuição no número de células ciliadas, às vezes totalmente desprovida de cílios (Figura 4). Ausência de mucosa foi vista em um caso (Figura 5).

A submucosa de todos os casos também foi minuciosamente estudada à microscopia óptica e eletrônica de transmissão. Observamos quatorze casos no total com pólipo do tipo fibro-inflamatório, caracterizados por intenso infiltrado inflamatório composto principalmente por linfócitos, plasmócitos e neutrófilos, abundância de fibroblastos, fibrose com finas fibras colágenas. (Figuras 6 e 7). Um caso de hiperplasia de glândulas seromucinosas (Figura 8) e dois casos com a submucosa rica em fibrose (pólipo fibrótico Figura 9).

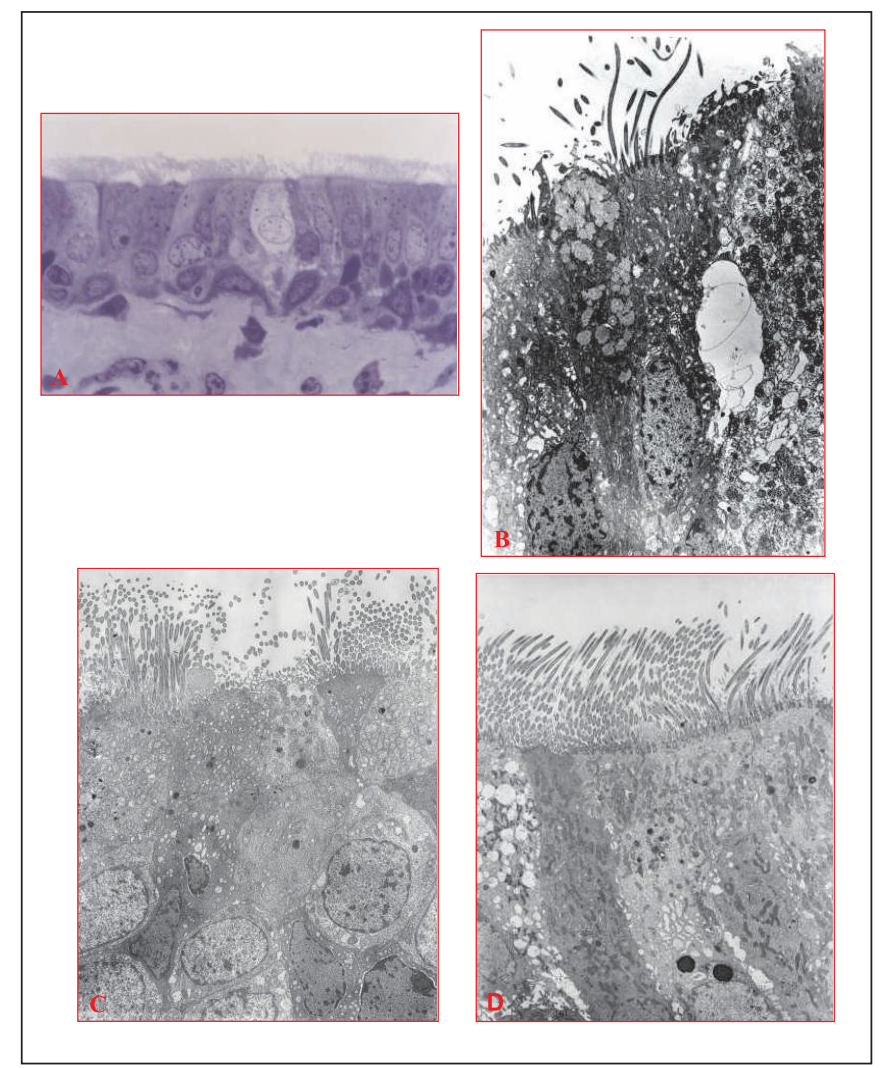

Figura 1. Epitélio respiratório normal encontrado na mucosa dos pólipos. A- MO (63X); B, C e D- MET: células ciliadas entremeadas com células não ciliadas e células caliciformes (4000X).

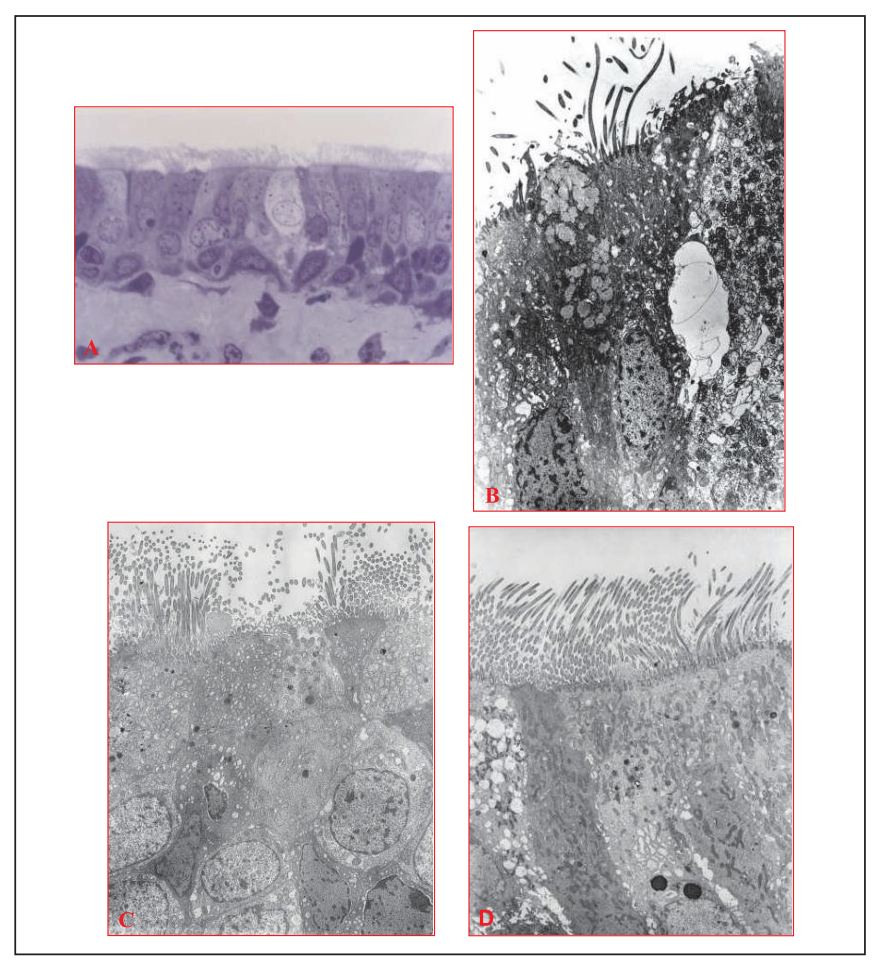

Figura 2.Epitélio respiratório atípico. MET - diminuição no número de cílios das células ciliadas (2.500X).

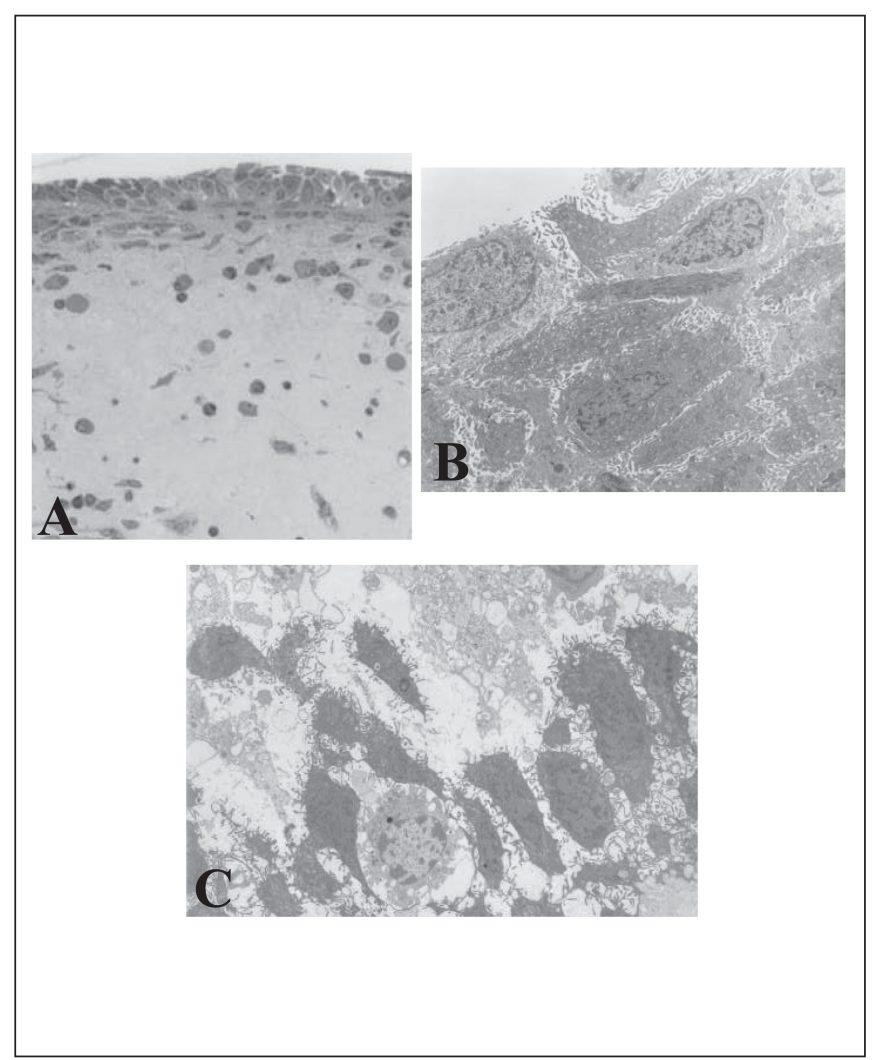

Figura 3. Epitélio metaplásico. A- MO (63X); B- MET: células achatadas (4.000X); C- MET: grandes espaços intercelulares com material amorfo; linfócito transitando pelo epitélio (2.500X). 


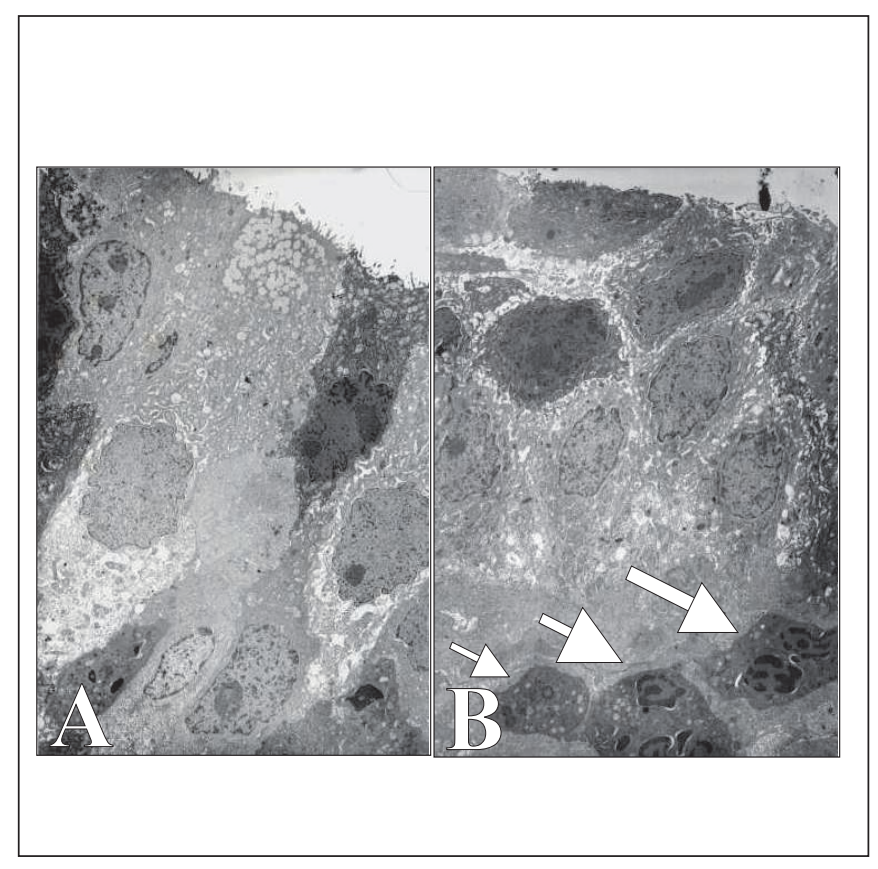

Figura 4. Epitélio misto. A- MET: epitélio respiratório atípico: diminuição no número de células ciliadas e cílios (6300X); B- MET: epitélio metaplásico: três macrófagos na submucosa subjacente (setas).

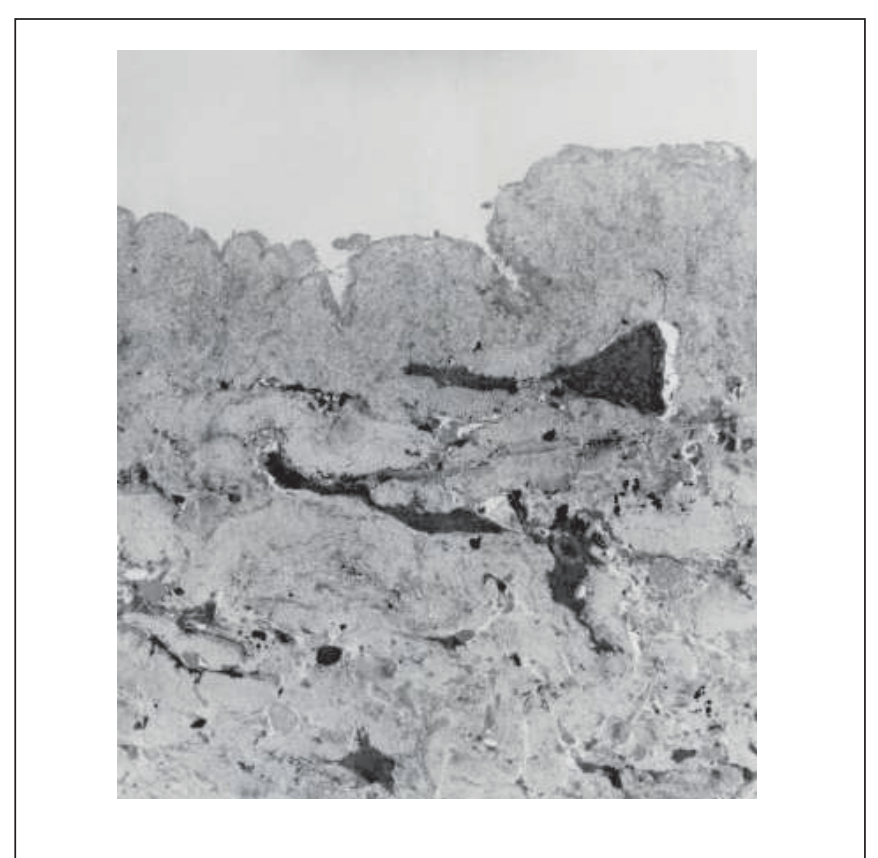

Figura 5. MET: ausência de mucosa; submucosa com áreas densas de fibrose $(5000 X)$.

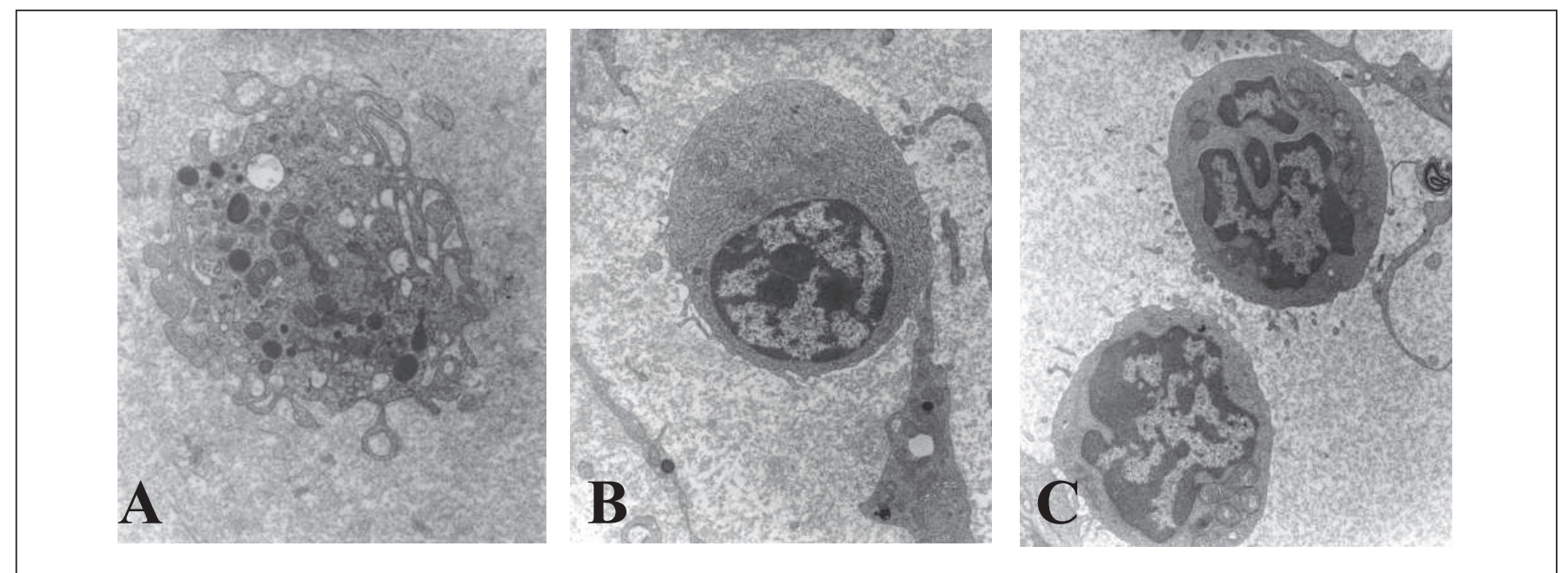

Figura 6. MET: células inflamatórias da submucosa. A- macrófago (10000X); B-plasmócito (6300X); C- linfócitos (8000X).

\section{DISCUSSÃO}

Apesar da PN ser reconhecida desde a antigüidade e de sua incidência relativamente alta em todas as populações, a sua fisiopatologia e o seu tratamento efetivo constituem, ainda hoje, um desafio. Os eventos que levam à formação dos pólipos ainda não foram totalmente elucidados, mas alguns progressos já podem ser visualizados.

\section{Idade e Sexo}

A idade média nos 2 grupos foi de 42,6 anos. Não foram verificadas diferenças entre a idade média do grupo alérgico ( 41,6 anos) e do grupo sem alergia (44 anos). Esta média acima de 30 anos também foi relatada por outros autores ${ }^{5-7}$, confirmando ser esta uma patologia muito rara em crianças e adolescentes.

Nos dezessete pacientes estudados, nove $(53,3 \%)$ 


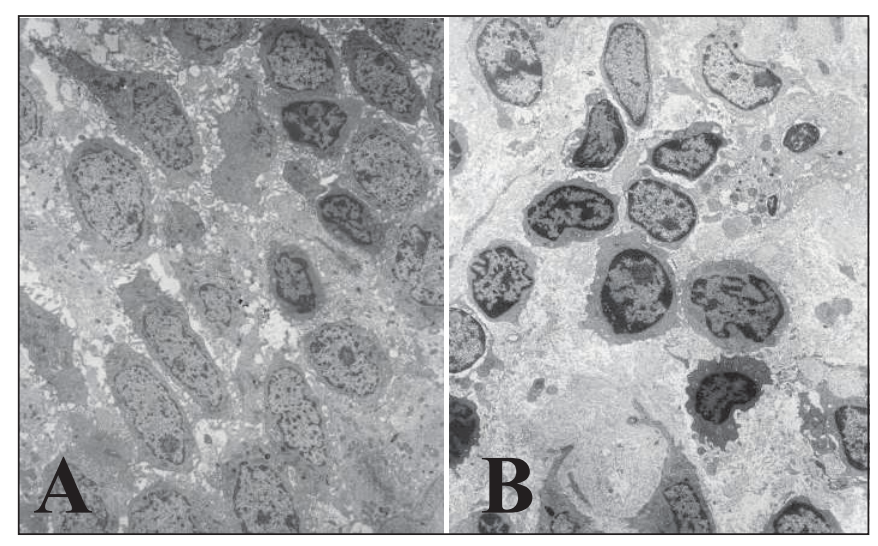

Figura 7. Pólipos fibro-inflamatórios. MET: submucosa rica em células inflamatórias. A- (2500X); B- (3200X).

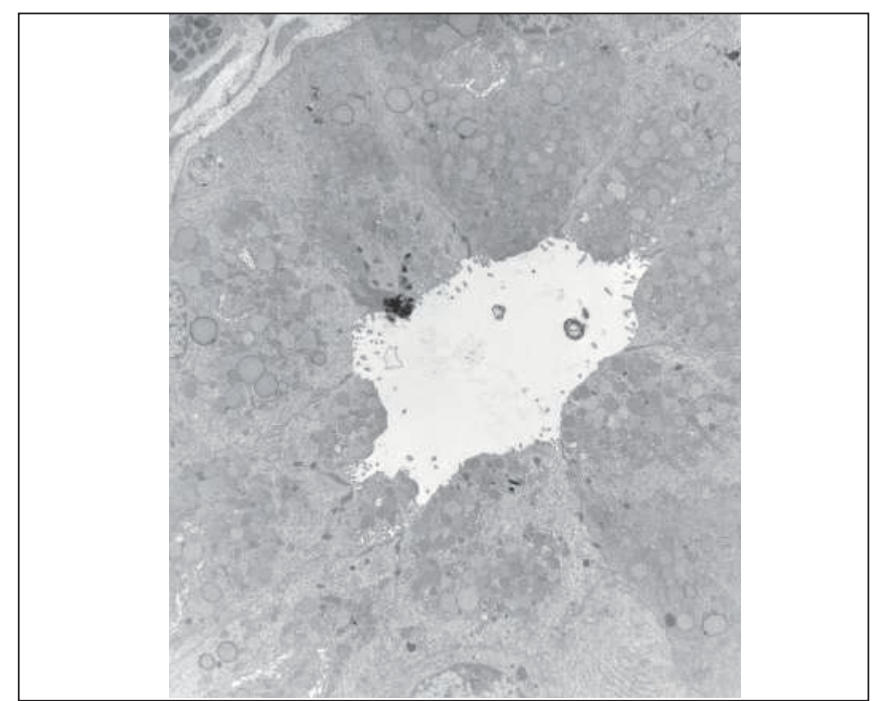

Figura 8. MET: Pólipo com hiperplasia de glândula serosa (3200X).

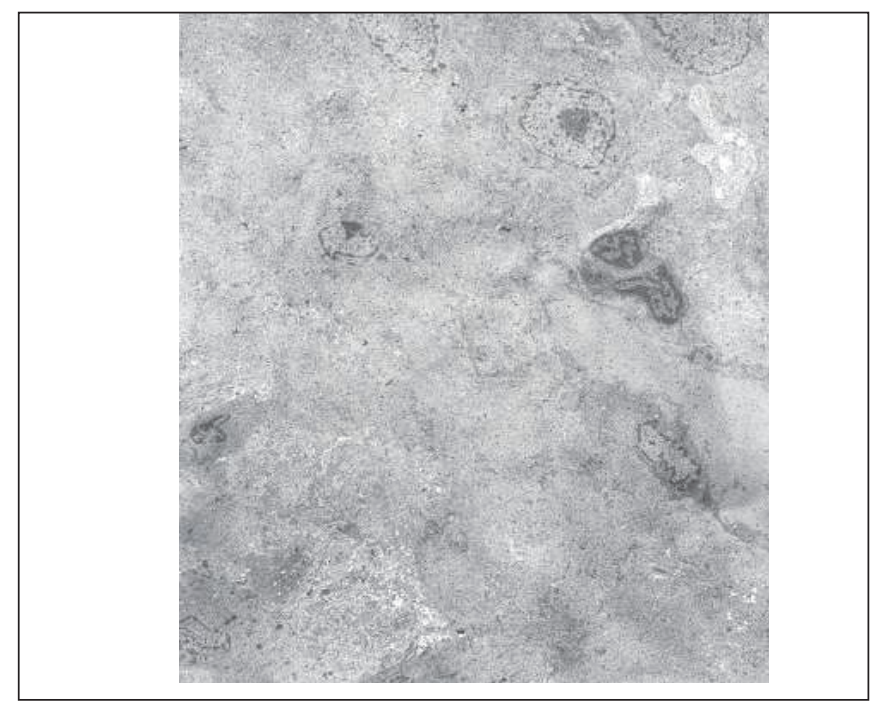

Figura 9. Pólipo fibrótico. MET. Submucosa com área densa em fibras colágenas (2500X). eram do sexo masculino e oito $(46,6 \%)$ do sexo feminino, estatística concordante com a literatura ${ }^{5-7}$. No Grupo 1 houve predominância do sexo masculino, enquanto no Grupo 2 a proporção foi a mesma.

\section{Testes Cutâneos}

Dos dezessete pacientes com polipose, oito apresentaram teste cutâneo positivo, este índice elevado só foi coincidente na literatura com o estudo de Wong et al. (1992) ${ }^{8}$ \#66\% \#, sendo que, neste estudo seu grupo de controle para pacientes com cirurgia sem ser de polipose a porcentagem de testes cutâneos positivos foi ainda mais elevada (74\%). Drake Lee et al. (1984) encontraram um índice de $44 \%$ de pacientes com polipose com testes cutâneos positivos. Outros autores concluíram que os índices de testes cutâneos positivos em pacientes com PN eram semelhantes aos da população geral (em torno de $30 \%)^{5-7}$

Já Gergen et al. (1991) ${ }^{10}$ testaram 16.204 pacientes para verificar 0 índice de atópicos numa população geral que foi de $20 \%$. Tal achado também foi observado por Keith et al. $(1995)^{11}$ que descreveram que pacientes com PN são mais atópicos que a população geral e menos atópicos que pacientes encaminhados para alergistas o que dá suporte a alergia como fator contribuinte dos PN, o que nos parece também mais coerente de se concluir.

\section{Microscopia Óptica}

Davidsson et al. (1993)4, estudando pólipos, fizeram uma classificação, a única que encontramos na literatura. Nossos resultados foram completamente diferentes: predominância absoluta de pólipos fibro-inflamatórios, o que talvez possa ser explicado por nossa amostra ter sido bem menor, ou por variações geográficas e/ou sociais das populações estudadas, ou principalmente pelo fato de que nossos pacientes estudados eram portadores de polipose já avançada, graus IV e V de Stamm (1995) ${ }^{12}$.

Quanto ao tipo histológico que encontramos com fibrose densa, o qual chamamos fibrótico (2 casos), ou se trata realmente de um novo tipo ou, na nossa opinião, até mais provável, seja devido à possível variação que ocorre dentro do mesmo pólipo em relação à sua estrutura, onde um corte histológico realizado em outro local possivelmente nos mostraria um dos quatro tipos já descritos.

Não encontramos diferenças significantes em relação à microscopia no que concerne aos grupos alérgicos e não alérgicos. Esses dados conferem com os de Ruhno et al. $(1990)^{13}$ que não verificaram diferenças no número de mastócitos entre $\mathrm{PN}$ de pacientes alérgicos e não alérgicos: Hamilos et al. (1995) ${ }^{14}$ que mostraram ausência de diferenças em relação à eosinofilia nos PNs de alérgicos e não alérgicos, e Park et al. (1998) ${ }^{15}$, que através de análise histoquímica do infiltrado celular dos PN, concluíram não haver diferenças entre os grupos alérgicos e não alérgicos. 


\section{Microscopia Eletrônica de Transmissão}

A maioria das nossas amostras de PN apresentou epitélio do tipo pseudoestratificado cilíndrico ciliado (47\%), seguido por epitélio do tipo pavimentoso estratificado metaplásico (23\%). Estes dados foram compatíveis com os estudos de Mygind et al. (1974) ${ }^{16}$ e Larsen \& Tos (1990) ${ }^{17}$. Dois casos apresentaram intensa atividade secretora com grande quantidade de mitocôndrias e complexo de Golgi bem desenvolvido, achados estes também encontrados por Cauna et al. (1972) $)^{18}$ mas não observados por Mygind et al. (1973 e 1974) $)^{16,19}$.

Em relação aos grupos 1 (alérgicos) e 2 (não alérgicos), não foram observadas diferenças entre os mesmos, o que também foi relatado por Mygind et al. (1974) e outros autores ${ }^{16,19}$.

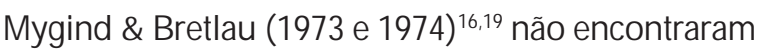
diferenças significativas ultraestruturais entre 0 epitélio normal da concha nasal inferior e o epitélio que recobre os pólipos. Entretanto, alguns detalhes morfológicos foram descritos por Cauna (1972) ${ }^{18}$, como espaços intercelulares distendidos por edema, vacuolização citoplasmática e acúmulo de grânulos de glicogênio em algumas células epiteliais, hiperplasia de células caliciformes, além da presença de células inflamatórias especialmente neutrófilos, mastócitos e eosinófilos.

\section{O Ambiente Inflamatório}

Segundo Norlander et al. (1996 e 1999) 2,20 muitas das pesquisas correntes de pólipos têm tocado no acúmulo de eosinófilos no tecido patológico. Embora a maioria dos pacientes com pólipo nasal tenha eosinofilia, expressão da doença é limitada às vias aéreas, que explica porque mecanismos subjacentes deveriam ser procurados no tecido e no local interação célula-célula. Grande soma de mediadores inflamatórios severos são encontrados no local microambiente constituído pelo pólipo e sua mucosa circundante ${ }^{21}$. Os efeitos combinados de citocininas e fatores de crescimento produzidos pelas células $T$ infiltrantes, fibroblastos, células epiteliais, ou células circulantes, eosinófilos, devem ser responsáveis por uma variedade de fases no processo de formação do pólipo. As citocinias GM - CSF (fator colônia estimulante granulócito-macrófago), IL-3 (interleucina-3) IL-5 (interleucina-5) providenciam mecanismos de importância para ativação e sobrevivência do eosinófilo22. GM - CSF derivados de fibroblastos parecem ter um papel chave naquele suporte de sobrevivência de eosinófilo e proliferação de macrófagos ${ }^{23}$. TGF - $\beta_{1}$ (fatores $\beta_{1}$ de crescimento transgênico) é produzido por eosinófilos no pólipo nasal e devem contribuir para o espessamento da membrana basal local, fibrose estromal e hiperplasia epitelial ${ }^{24-26}$. Os efeitos são aparentemente complexos e algumas vezes contraditórios, embora a soma maior de GM - CST e IL-5 nos pólipos sugeririam uma predominância de respostas tipo cel Th2. Células T clonadas de pólipos nasais têm na média um padrão Th1 com uma alta taxa Y. interferon (IFN-Y) interleucina 4 (IL-4), similar à situação em reações de hipersensibilidade tipo tardias e asma intrínseca.

Entretanto, eosinófilos não são um pré-requisito para 0 desenvolvimento de pólipo nasal. Em pacientes com pólipos secundários, a fibrose cística ou rinossinusite maxilar crônica devido à infecção dentária, neutrófilos são as células inflamatórias mais numerosas. Apesar de algumas diferenças histológicas entre pólipos eosinófilos e pólipos associados com FC, a estrutura básica é similar em ambos os tipos. Isso sugere que naquelas doenças, onde as etiologias eram muito diferentes, mecanismos patogênicos similares devem governar a resposta da mucosa nasal (via final comum). Um persistente estado de inflamação é um fator comum em todas as formas de PN.

As diferenças entre nossos resultados e os obtidos por Davidsson e Hellquist ${ }^{4}$ podem refletir uma variabilidade entre as populações estudadas. Entretanto, nossa casuística de 17 casos não permite extrapolar os resultados como significativos de uma população.

Pode-se sugerir que os vários tipos histológicos de pólipos encontrados seriam estágios distintos de evolução da mesma doença. A presença e, principalmente, a manutenção de fatores locais como infecção bacteriana crônica podem resultar em alterações qualitativas da resposta inflamatória local levando à padrões histológicos mais "crônicos" como o observado no pólipo fibro-inflamatório. Tal hipótese é reforçada pelo fato de que, neste estudo, todos os pacientes apresentavam história crônica de doença infecciosa antes de serem submetidos à cirurgia e coleta dos espécimes estudados.

\section{CONCLUSÕES}

1. Pacientes com PN ap resentam índices de testes cutâneos positivos iguais ou maiores que a população geral, o que pode sugerir uma possível correlação entre polipose e alergia;

2. Não há diferenças histológicas ou ultra-estruturais entre pólipos de pacientes alérgicos ou não alérgicos, o que sugere ser a alergia um fator contribuinte, mas não primordial na fisiopatologia;

3. 0 epitélio de revestimento dos pólipos mais freqüentemente encontrado foi o epitélio respiratório normal;

4. Pólipo Fibro-inflamatório: As características do infiltrado inflamatório, em especial a abundância de fibroblastos e fibrose, podem significar que o processo inflamatório crônico é o responsável pelas alterações morfológicas descritas;

5. Pólipo Eosinofílico: Nenhum caso encontrado. A cronicidade dos pacientes incluídos neste estudo pode ser uma explicação plausível, pois a presença de edema e infiltrado eosinofílico característicos desta categoria seriam etapas mais "iniciais" na gênese do pólipo; 
6. Pólipo Fibrótico: Da mesma forma, a presença de inflamação crônica pode estar relacionada com os achados morfológicos encontrados, significando que a fibrose densa possa representar um processo inflamatório em vias de resolução;

7. Com base nestes resultados, podemos concluir que a gênese dos pólipos na PN é dependente do processo inflamatório e que este, provavelmente, evolui de fomas mais iniciais para formas mais crônicas. As várias categorias descritas por Davisson e Hellquist ${ }^{4}$ podem significar etapas de um processo contínuo e evolutivo de transformação relacionado com a cronicidade da inflamação.

\section{REFERÊNCIAS BIBLIOGRÁFICAS}

1. Caplin I, Haynes JT, Spahn J. Are nasal polyps an allergic phenomenon? Ann Allergy 1971;29: 631-4.

2. Norlander $T$, Brönnegard M, Stierna P. The relationship of nasal polyps infection and inflamation. American Journal of Rhinology 1999;13(5): 349-55.

3. Bernstein J.M, Gorfien J, Noble B. Role of allergy in nasal polyposis: a review. Otolaryngol Head Neck Surg 1995;113(6): 724-32.

4. Davidsson A, Hellquist HB. The so-called "allergic" nasal polyp. Orl J Relat Spec 1993;SS:30-5.

5. Jamal A \& Marant AGD. Atopy and nasal polyposis. J Laryngol Otol $1987 ; 101: 355-8$

6. Granstrom G, Jacobsson E, Jeppsson PH. Influence of allergy asthma and hypertension on nasal polyposis. Acta Otoloryngol 1992;492: 22-7.

7. Voegels R. Tese de doutorado, Universidade de São Paulo; 1998.

8. Wong $D \&$ Dolovich J. Blood eosinophilia and nasal polyps. Am J Rhinology 1992;6:195-8.

9. Drake-Lee A, Lowe D, Swantson A, Grace A. Clinical profile and recurrence of nasal polyps. J Laryngol Otol 1984;98:783-93.

10. Gergen PG, Turkeltang PC. The association of allergen skin test reactivity and respiratory disease amoung whites in the U.S. population. Arch Intern Med 1991;151: 487-92.

11. Keith PK, Conway M, Evans S, Edney P, Jennings B, Andersson B, Dolovich J. A doubleblind comparison of intranasal budesonide dry powder vs placebo in nasal polyposis. J Allergy Clin Imunol 1995;95:204 (abstract).
12. Stamm AC. Microcirurgia Naso-Sinusal. Rio de Janeiro: Editora Revinter Ltda.; 1995. $436 \mathrm{pp}$.

13. Ruhno J, Howie $K$, Anderson M, Andersson B, Vanzieleghem $M$, Hitch D, Lapp P, Denburg J, Dolovich J. The increased number of ephitelial mast cells in nasal polyps and adjacent turbinates is not allergy-dependent. Allergy 1990;45:370-4.

14. Hamilos DL, Leung DYM, Wood R, Cunningham L, Bean DK, Yasjruel Z, Schotmam E, Hamid Q. Evidence for distinct cytokine expression in allergic versus nonallergic chronic sinusitis. J Allergy Clin Immunol 1995;96:537-44.

15. Park HS, Kim H-Y, Nahm DH, Parkk, Suh K-5; Yim HE. The presence of atopy does not determine the type of cellular infiltrate in nasal polyps. Allergy and asthma proc 1998;19: 373-7.

16. Mygind N, Bretlan P, Sorensen $H$. Scanning electron microscopic studies of nasal polyps. Acta Otolaryng 1974;78:436-43.

17. Larsen $P \&$ Tos M. Nasal polyps. Epithelium and goblet cell. Density Laryngoscope 1990;99:1274-80.

18. Cauna N, Hinderer KH, Manzetti GW, Swanson EW. Fine structure of nasal polyps. Ann Otol 1972;81:41-57.

19. Mygind $N \&$ Bretlau P. Scanning electron microscopic studies of the human nasal mucosa in normal persons and in patients with perennial rhinitis. I: Cillia and Microvilli. Acta Allergol "Kbh" 2829 - (1974) Ibid. II: Secretion. Acta Allergol "Kbh" in press.

20. Norlander T, Westrin KM, Fukami M, Stierna P, Carlsöö B. Experimentaly induced polyps in the sinus mucosa: A strutural analysis of the initial stages. Laringoscope 1996;106:196-203.

21. Dolovich J, Ohtoshi T, Jordana M, Gauldie J, Denburg J. Nasal polyps: local inductive microenvironment in the phatogenesis of inflammation. Copenhagen: Munksgaard; 1990. p.233-41.

22. Jordana M, Dolovich J, Ohno I et al. Nasal poliposis: A model for chronic inflamation. Asthma and Rhinitis. Busse W Holgate S (Eds) Blackwell Science 1995; p.156-64.

23. Vancheri C, Ohtoshi T, Cox G. Neutrophilic differentiation inducced by human upper airway fibroblast-derived granulocyte/macrophage colony-stimulating factor (GM-CSF). Am J Resp Cell Mol Biol 1991;4:11-7.

24. Elovic A, Wong D, Weller $P$ et al. Expression of transforming growth factors-a and b-1 messenger RNA and product by eosinophils in nasal polyps. J Allergy Clin Immunol 1994;93:864 9 .

25. Allen JS, Eisma R, Leonard G, Lafreniere D, Kreutzer D. Interleukin8 expression in human nasal polyps. Otolaryngol Head Neck Surg 1997;117(5):535-41.

26. Rhee CS, Lee $\mathrm{CH}$, Min YG. Cytokine gene expression in nasal polyps. Ann Otol Rhinol Laryngol 1998;107:665-70. 